Check for updates

New York

Cite this as: BMJ 2021;375:n2693

http://dx.doi.org/10.1136/bmj.n2693

Published: 04 November 2021

\title{
Covid-19: US doctors begin administering vaccine to children aged 5-11
}

\section{Janice Hopkins Tanne}

US physicians began giving the Pfizer BioNTech vaccine to children aged 5-11 on 3 November, immediately after the Food and Drug Administration (FDA) and the Centers for Disease Control and Prevention (CDC) authorised its use.

There are about 28 million children in that age group in the US. They will receive a $10 \mu \mathrm{g}$ dose (about one third the adult dose) of the vaccine followed by a second jab three weeks later. Previously, vaccination had been approved only for children over 12 .

President Joe Biden said, "Children make up one quarter of the cases in this country. And, while rare, children can get very sick from covid-19. Some-a few-can end up in hospital. But they don't have to."

The FDA had previously authorised the Pfizer BioNTech vaccine for children aged 5-11 and the CDC's advisory committee on immunisation practices recommended the child dose on 2 November. CDC director Rochelle Walensky immediately approved it, saying, "We have taken another important step forward in our nation's fight against the virus that causes covid-19. We know millions of parents are eager to get their children vaccinated. As a mom, I encourage parents with questions to talk to their paediatrician, school nurse, or local pharmacist to learn more about the vaccine and the importance of getting their children vaccinated."2

Anticipating authorisation, Biden said that the administration had prepared and shipped vaccines to local sites across the nation. Unlike the adult vaccines, which were administered in large sites, the children's vaccine will be given through doctors' offices, school clinics, and local pharmacies, some of which will be open at nights and on weekends. The vaccine will be free. President Biden said that the government had already secured enough vaccines for every child in the US aged 5-11.

The vaccine drive will mean a good year for Pfizer. The company said on 2 November that it expected \$36bn in sales of the vaccine in 2021 and \$29bn more next year. ${ }^{3}$

Gerald Harmon, president of the American Medical Association, said the vaccine authorisation was "a critical step toward protecting this population from covid-19 infections. There is overwhelming evidence showing that covid-19 vaccines are safe and effective but we know many parents and families will have questions. We encourage parents to speak with their child's physician and review trusted resources, such as getvaccineanswers.org, to get the information they need to make an informed decision."

Harmon said he hoped vaccinating millions of children would reduce their risk of covid-19 infection, hospital admission, and death. He noted stark disparities among children: rates of hospital admission were three times higher for Black, American Indian, Alaska Native, and Hispanic and Latinx children compared with white children. ${ }^{4}$

The American Academy of Paediatrics also supported the CDC's decision, saying that it "will protect children's health and allow them to fully engage in all the activities that are so important to their health and development." It said children who had had a covid-19 infection should receive the vaccine "to prevent a second infection and to lower the risk of severe illness and hospital admission.” It suggested children receive the covid- 19 vaccine and the flu vaccine during a single visit to a doctor or clinic. But it also said that mask wearing should continue. ${ }^{5}$

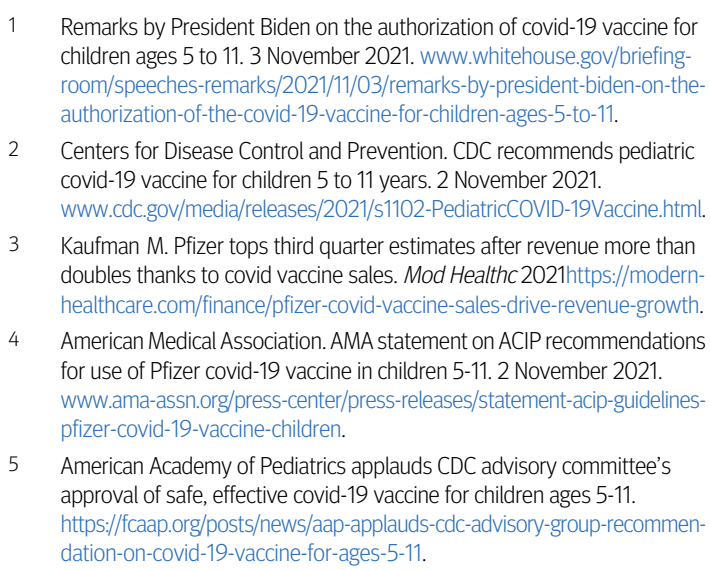

Remarks by President Biden on the authorization of covid-19 vaccine for children ages 5 to 11. 3 November 2021. www.whitehouse.gov/briefingroom/speeches-remarks/2021/11/03/remarks-by-president-biden-on-theauthorization-of-the-covid-19-vaccine-for-children-ages-5-to-11.

2 Centers for Disease Control and Prevention. CDC recommends pediatric covid-19 vaccine for children 5 to 11 years. 2 November 2021. www.cdc.gov/media/releases/2021/s1102-PediatricCOVID-19Vaccine.html.

3 Kaufman M. Pfizer tops third quarter estimates after revenue more than doubles thanks to covid vaccine sales. Mod Healthc 2021https://modernhealthcare.com/finance/pfizer-covid-vaccine-sales-drive-revenue-growth.

4 American Medical Association. AMA statement on ACIP recommendations for use of Pfizer covid-19 vaccine in children 5-11. 2 November 2021. www.ama-assn.org/press-center/press-releases/statement-acip-guidelinespfizer-covid-19-vaccine-children.

5 American Academy of Pediatrics applauds CDC advisory committee's approval of safe, effective covid-19 vaccine for children ages 5-11. https://fcaap.org/posts/news/aap-applauds-cdc-advisory-group-recommendation-on-covid-19-vaccine-for-ages-5-11.

This article is made freely available for use in accordance with BMJ's website terms and conditions for the duration of the covid-19 pandemic or until otherwise determined by BMJ. You may use, download and print the article for any lawful, non-commercial purpose (including text and data mining) provided that all copyright notices and trade marks are retained. 